\title{
Prosthetic Lumbar disc replacement for degenerative disc disease
}

\author{
Arvind G. Kulkarni, Ashish D. Diwan
}

Spine Service, Department of Orthopaedic Surgery, St George Hospital Campus, University of New South Wales, Sydney, Australia

\begin{abstract}
Mechanical articulated device to replace intervertebral disc as a treatment for low back pain secondary to disc degeneration has emerged as a promising tool for selected patients. The potential advantages are prevention of adjacent segment degeneration, maintenance of mobility as well as avoidance of all the complications associated with fusion. The short-term results have been comparable to that of fusion, a few mid-term results have shown mixed outcome, but information on long-term results and performance are not available at present. The rationale for lumbar disc arthroplasty, indications, contraindications, the various artificial devices in the market and the concepts intrinsic to each of them, basic technique of insertion, complications are discussed and a brief summary of our experience with one of the devices is presented.
\end{abstract}

Key words: Low backpain,chronic back pain, spinal fusion, lumbar disc replacement, disc replacement, disc degeneration.

\section{Degenerative disc disease}

The lumbar spine is designed to provide trunk motion, mechanical support to the body and protect the neural elements. Biomechanical studies demonstrate that the anterior spinal column consisting of vertebral bodies and intervertebral discs bear most of the body weight in the upright position while the facet joints bear upto $16 \%$ of the axial load. ${ }^{[1]}$ The intervertebral disc is the primary stabilizer of a functional spinal unit by providing constrained mobility to its segments. The intervertebral disc can become a source of pain, commonly referred to as 'discogenic pain' as a result of disc degeneration. The mechanical and complex cellular events involved in intervertebral disc degeneration and the possible role played by intrinsic, extrinsic as well as genetic factors in its manifestation has been summarized by Chung et al. ${ }^{[2]}$ Morphological changes involve dehydration of the nucleus pulposus $[\mathrm{NP}]$ with formation of clefts and fissures, disorganization of the collagen fibrils of the annulus fibrosus $[\mathrm{AF}]$ with associated myxomatous degeneration and sclerosis of the endplate. In the later stages, the NP and AF become indistinguishable from each other and the intervertebral disc loses its elasticity. At the cellular level, diminishing diffusion across the endplate as a result of sclerosis leads to insufficient oxygenation and lactate accumulation thereby creating an acidic environment. As a result, cellular longevity and matrix regeneration is impaired. The synthesis of proteoglycan molecule which determines the water content of the intervertebral disc is diminished resulting in loss of its viscoelastic property. Though these age-related changes occur universally, it is difficult to predict at what stage of the degenerative cascade the condition becomes painful.

\section{Rationale}

Chronic back pain is a major cause of social and financial concern since it is associated with impaired quality of life, loss of productivity and large health care expenses. To our knowledge, the exact health costs related to back pain have not been estimated in India. However, a cross-sectional study of 418 industrial (tannery) workers in Kanpur revealed that low-back pain was the most common occupational disease $(61 \%)$ followed by asthma $(38 \%)$, dermatitis $(23 \%)$ and chronic bronchitis $(14 \%){ }^{[3]}$ The study also revealed that there was an association between manual lifting over $20 \mathrm{~kg}$ and low-back pain (Odds Ratio $[\mathrm{OR}]=3.5$ ) and sickness absenteeism was significantly associated with low backpain $(\mathrm{OR}=3.3)$. Backache also forms the second common condition after digestive complaints for which alternative unconventional therapies are utilized at the tertiary care level Indian hospitals. ${ }^{[4]}$ Sharma et al ${ }^{[5]}$ carried out a prospective study to estimate the incidence of low back pain in patients attending outpatient department in a major tertiary care hospital. Out of 11234 patients in one year, 2594 (23\%) had low back pain. Patients with spinal deformity and herniated nucleus pulposus were excluded from the study. All patients had used NSAIDs at some stage and $64 \%$ were advised exercises. About $57 \%$ of patients were heavy manual workers, $26 \%$ had to change or leave their 
profession and $38 \%$ did not enjoy their present job.

Spinal fusion has been the standard of care for unrelenting back pain secondary to disc degeneration. Though spinal fusion has stood the test of time, it has some concerns. Post-operative recovery is relatively slow; pseudo-arthrosis, bone-graft site morbidity and instrument related problems are observed in a large percentage of cases. ${ }^{[6,7]}$ Though the incidence of adjacent level degeneration following spinal fusion remains unresolved, biomechanical and kinematic investigations demonstrate increased load and movement adjacent to fused segments. ${ }^{[8]}$ For a long time there was no alternative between taking chronic medication and undergoing a spinal fusion operation for the diagnosis of degenerative disc disease in the absence of central canal or foraminal stenosis. Disc replacement is an option for patients with chronic back pain who meet the selection criteria, (subsequently discussed). The benefits of motion preservation and protection of adjacent levels from non-physiologic loading make prosthetic replacement of the disc a potentially attractive choice.

\section{Biomechanical rationale}

A motion segment consists of 6 degrees of freedom: 3 in translation and 3 in rotation (Figure 1). Loading modes produced in the segment are axial compression, flexion-extension, lateral bending and torsion. A viscoelastic structure such as the disc exhibits hysteresis. The phenomenon of hysteresis describes a loss of energy when a structure is subject to loading-unloading cycles (Figure 2). The viscoelastic characteristic of the spine absorbs and damps the applied energy, therefore when the spinal segment is unloaded, some energy is lost (dissipated by nucleus). With disc degeneration the nucleus pulposus reduces in volume as a consequence of decreased proteoglycan and water concentration, resulting in a loss of intradiscal pressure and a change in the elastic modulus gradient. Degeneration alters the fatigue-recovery of the disc. The lack of viscoelasticity causes the spine to creep to its final deformation in an instantaneous (step function) manner, which is more characteristic of an elastic structure, rather than the gradual logarithmic fashion with sufficient damping which is characteristic of a viscoelastic structure. There is a reduction in the ability of the disc to attenuate shock and provide an even stress distribution. Since the deformation in creep and in relaxation is reached more instantaneously, the hysteresis is smaller. (i.e. less energy absorption) [Figure 3]. The load borne by the annulus subsequently increases and it undergoes wear and tear. This phenomenon of disc incompetence transfers the load to the facet joints which may lead to facet joint degeneration. The solution to re-establish the spinal biomechanics is to replace the degenerated disc with a mechanical device with the aim of restoration of intervertebral disc height, lumbar facet joint structure and function as well as range of motion of the motion segments.

\section{Indications and contraindications}

The indication for lumbar total disc replacement is a patient

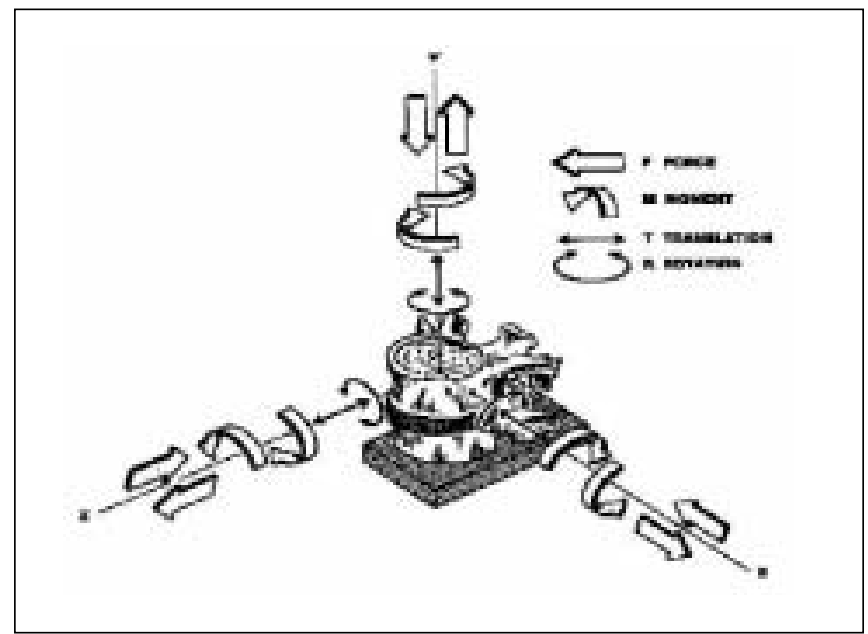

Figure 1: Motion segment with six degrees of freedom (with permission from Prof. M. Panjabi)

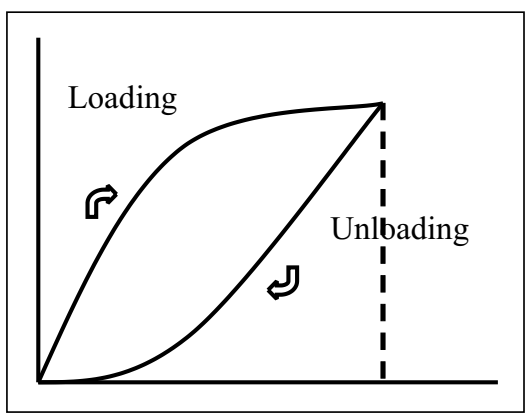

Figure 2: Hysteresis curve demonstrating absorption and dissipation of equal amount of applied energy when a normal intervertebral disc

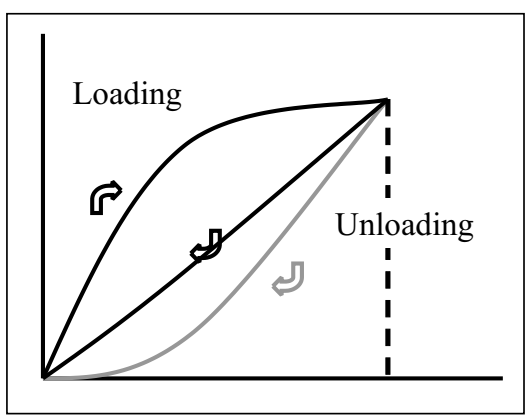

Figure 3: Loss of viscoelastic property as a result of disc degeneration leads to absorption of energy by creep deformation and more instantaneous relaxation causing a smaller hysteresis curve.

with severe, chronic disabling back pain with single and/ or twolevel degenerative disc disease who has failed at least six months of non-operative treatment including physiotherapy, facet joint injections, acupuncture, bed-rest, anti-inflammatory and analgesic medication, back school training and all other possible nonsurgical efforts to ease back pain. ${ }^{[9]}$ Objective evidence of degenerative disc disease should be demonstrated using radiographs, MRI and/ or CT scan. Provocative discography may need to be carried out to corroborate the clinical and radiological findings. ${ }^{[9]}$

There are certain age limitations for the procedure. In patients 
less than 18 years of age, skeletal maturation and for people above 60 years of age co-existent osteoporosis, facet arthrosis and spinal stenosis are considerations. Facet arthropathy has been appreciated as a major contraindication since pain from posterior elements may not be resolved by total disc replacement. The outcomes of total disc replacement on patients with mild facet arthrosis are inferior ${ }^{[10-12]}$ and progression of facet arthrosis has been noticed in one series after total disc replacement. ${ }^{[12]}$ On the other hand, Kostuik et $\mathrm{l}^{[13]}$ believe that mildly degenerate facet joints get unloaded by restoration of disc height with total disc replacement and this diminishes the pain component arising from them. Significant osteoporosis and endplate irregularities (e.g. Schmorl's nodes) can lead to implant subsidence and contribute to poor outcomes following total disc replacement.

The application of present generation prostheses in the presence of spinal deformities and instability patterns such as spondylolysis, spondylolisthesis, post-operative instability is contraindicated since the intervertebral disc prosthesis are not designed to correct spinal deformities or treat instabilities. Morbid obesity is a relative contraindication due to the difficulty in approaching the lumbar spine anteriorly. The presence of radicular symptoms as a result of contained herniation is probably not a contraindication as long as a complete decompression up to the posterior annulus is performed. Sequestrated herniation of the nucleus pulposus, a prolapse sufficient to cause cauda equina syndrome, foraminal and central canal stenosis are presently contraindicated for total disc replacement as they require a posterior decompression. Infection is a definite contraindication, though failed back syndrome with epidural fibrosis is considered by some as a relative contraindication. ${ }^{[9]}$ The success of total disc replacement is directly proportional to the consideration given to patient selection. ${ }^{[14]}$ Though disc replacement is a promising technology, it is reasonable to consider that it is not a panacea for all kinds of spinal disorders. The indications for disc replacement are narrow enough to estimate that only $5 \%$ of consecutive patients selected for lumbar surgery in fact met with the selection criterion for total disc replacement. ${ }^{[15]}$

\section{Total disc replacement}

Majority of the annulus fibrosus and all of nucleus pulposus is removed and replaced with an articulated mechanical device. There are five designs available in the market currently. They either have metal-on-polymer or metal-on-metal bearing surfaces. The devices have metal base-plates that bond to the bony endplates of the vertebrae. The five artificial total dises are briefly discussed here.

\section{Prodisc: (Spine solutions/Synthes) (Figure 4)}

The Prodisc prosthesis is a semiconstrained device with a polished superior articulating surface and an ultra high molecular weight polyethylene core fixed at surgery to the inferior endplate. The Prodisc I was first implanted in 1990. Prodisc II, the current device is an advancement of the previous design in that the endplates are made of cobalt-chromium-molybdenum (Co-Cr-Mo) (instead of titanium alloy), have a single large keel in the centre augmented with two lateral spikes (instead of two lateral keels) and minor advancements in the technique of insertion. Prodisc II is available in two sizes, three heights and two different angles of lordosis $\left(6^{\circ}\right.$ and $\left.11^{\circ}\right)$. The center of rotation is located just below the endplate of the inferior vertebra with concentric rotation of the facet joints during movement. The range of motion is $13^{\circ}$ of flexion, $7^{\circ}$ of extension and $10^{\circ}$ of lateral bending. Axial rotation is relatively free and is restrained by the facet joints and surrounding soft-tissue tension, particularly that afforded by the remaining lateral annular fibres. The prosthesis does not translate and this may protect the facet joints from antero-posterior shear stress. Delamarter et $\mathrm{al}^{[16]}$ reported an interim analysis of a multicenter prospective randomized study of ProDisc versus circumferential fusion (standard of care) for one- and two-level degenerative disc disease. Randomization was performed using a 2 to 1 ratio of disc replacement procedure to a fusion procedure. The analysis includes data up to 6 months from the first 53 randomized patients. Disc replacement patients reported significantly less pain (Visual Analogue Scale) and disability (Oswestry) in the early period following surgery compared to fusion patients and this difference disappeared by 6 months. When compared to fusion, the disc replacement allowed preservation of motion at L4-L5 with a similar trend at L5-S1. The results of two years FDA study of this set of patients is ready to be published.

\section{SB Charite (Depuy Spine, Johnson and Johnson, Raynam, MA) (Figure 5)}

SB Charite prosthesis has been used extensively following its initial implantation in 1982. Its name is derived from the two designers Kurt Schellnack and Karin Buttner-Janz who did the development work at the Charite Hospital in Berlin, Germany. It was redesigned in 1985 as the SB Charite II with lateral extensions to prevent subsidence. However, the tABLEdevice failed again in some patients as a result of fracture of the lateral extensions in some patients. In 1987 the prosthesis was redesigned to its present form as the SB Charite III. The device consists of a free-floating biconvex ultrahigh molecular

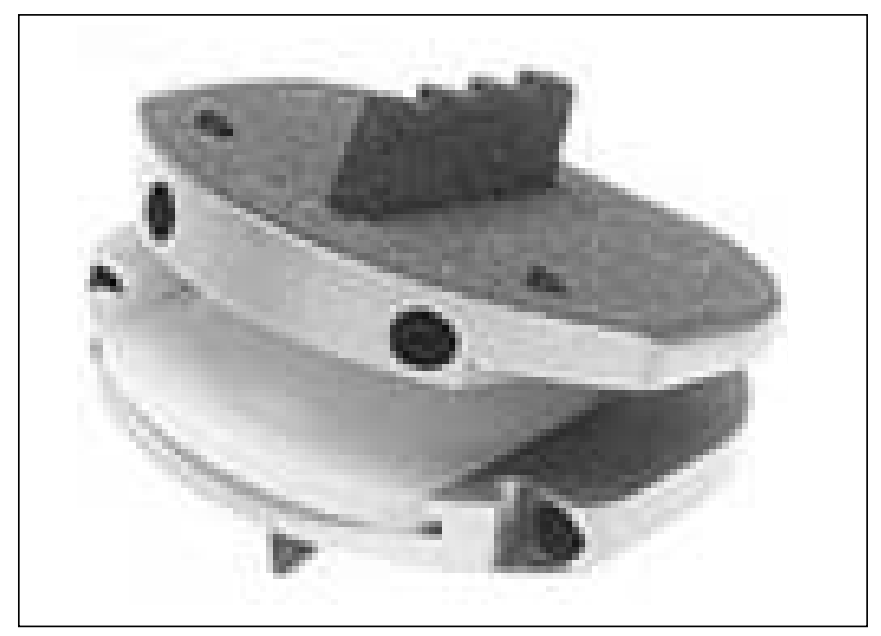

Figure 4: The Prodisc II prosthesis (Synthes Spine) 


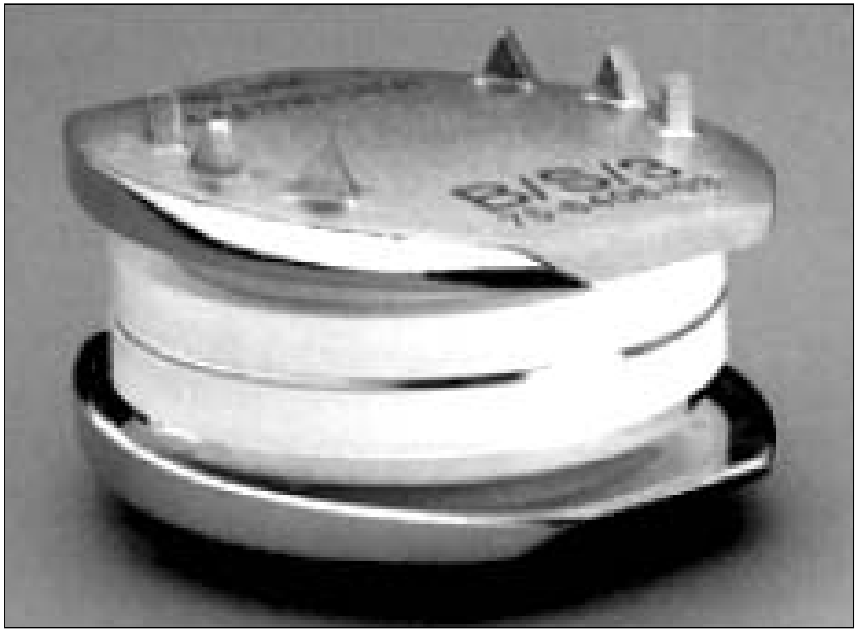

Figure 5: The SB Charite III prosthesis (Depuy Spine, Johnson \& Johnson Co).

weight polyethylene spacer sandwiched between two concave cobalt chromium end plates. The spacer can slide and rotate with modest constraint, thus varying the IAR (instantaneous axis of rotation) of the disc and replicating a normal disc. The metal plates anchor to the endplates by way of three small spikes positioned anteriorly and three posteriorly. The surface was modified to allow bony in-growth for better anchoring of the end plates. More than 6,500 dises have been implanted worldwide. A 24-month randomized controlled trial comparing the outcomes of SB Charite and anterior lumbar inter-body fusion (ALIF) with BAK was performed. The patients were randomized to receive either SB Charite device or BAK cage (ALIF) in the ratio of $2: 1$. At follow-up, $63 \%$ of patients in the Charite group and $53 \%$ of subject in the BAK fusion group were considered a clinical success. On the visual analogue scale for pain, $75 \%$ of Charite subjects and $70 \%$ of BAK cage subjects had greater than 20-mm improvement. An average range of motion of $7.4^{0}$ was recorded in the Charite subjects.

\section{Maverick (Medtronic Sofamor Danek, Inc, Memphis, TN) [Figure 6]}

This prosthesis is a semi-constrained ball and socket, metal-onmetal device with a posterior centre of rotation which matches that of the dise segment. The first implantation of Maverick prosthesis was in January 2002.

\section{Flexicore: (Stryker Spine) [Figure 7]}

Flexicore is a constrained ball and socket, metal-on-metal device with a posterior centre of rotation. The globular metal head is press-fit onto a cylinder jetting out from the superior base-plate, passes through a novel conical device and articulates with a metallic socket carved within a cylinder in the inferior baseplate. The conical device is called the shield and provides constraint to the motion of the ball in the socket by snapping to the outer rim of the socketcylinder of the inferior baseplate.

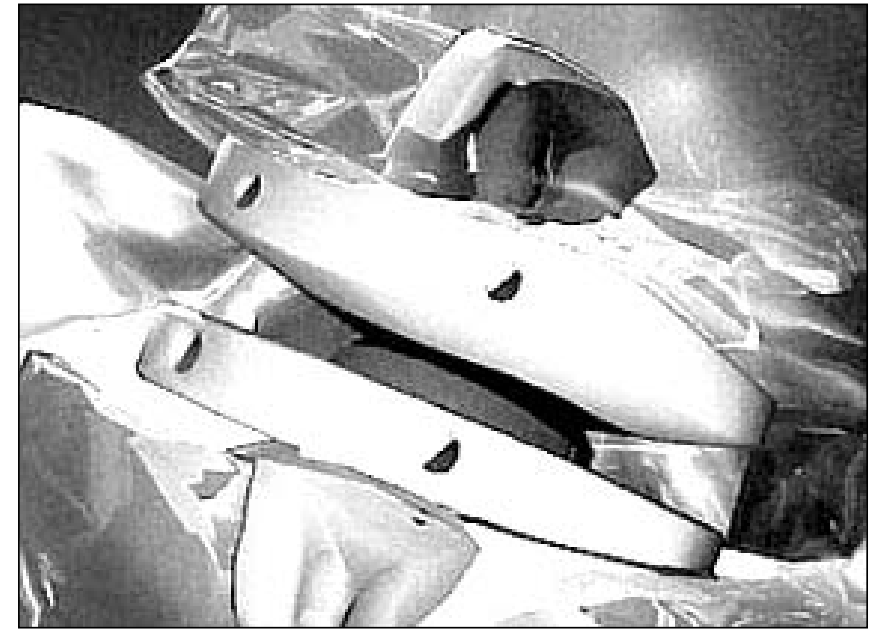

Figure 6: The Maverick prosthesis (Medtronic Soamor Danek)

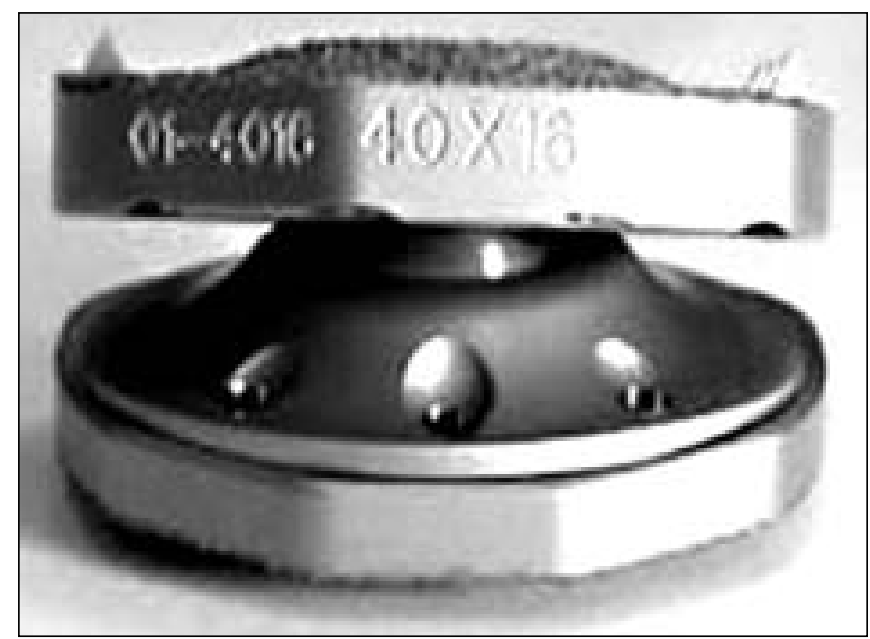

Figure 7: The flexicore (Stryker spine)

\section{Mobidisc (LDR Medical, Cedex 9-France) (Figure 8)}

Mobidisc has a mobile polyethylene that is contained by peripheral metal constraints. The concept is similar to a mobile meniscal bearing total knee prosthesis. The polyethylene core finds it ideal balance position according to the constraint applied by self-centring of the mobile insert on the inferior plate and selfadjustment of the superior plate positioning versus inferior plate.

The Mobidisc, Maverick and Flexicore are under trial.

\section{Surgical technique}

The total lumbar disc prostheses are implanted using an anterior approach, similar to pertaining to an ALIF (Anterior Lumbar Interbody Fusion). Implantation of Prodisc prosthesis is discussed.

Patient positioning: Optimal patient positioning assumes relevance to ensure safe access to the disc space. The patient is positioned in a modified 'Da Vinci' position with arms abducted and elevated $90^{\circ}$. 


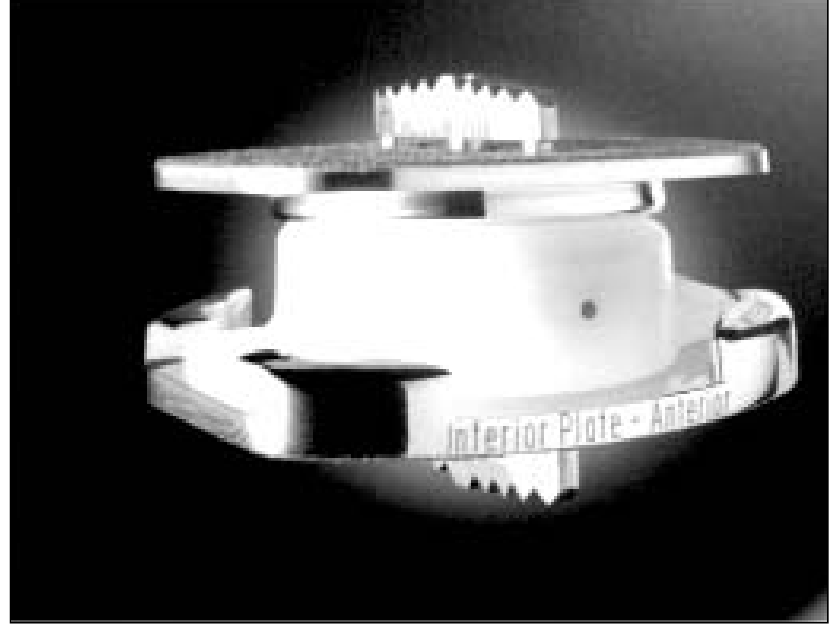

Figure 8: The Mobidisc prosthesis (LDR Medical)

Approach: A minimally invasive approach is utilized to access the anterior lumbar spine. A vertical incision is employed for all levels above L5-S1 and multiple level disc replacements including L5-S1 level. A transverse bikini incision is used for L5-S1 disc space access. Anterior lumbar spine is reached by either a retroperitoneal (most common; accessed from the right side in the male patients at L5-S1 level to avoid injury to the hypogastric plexus) or trans-peritoneal approach. The levels above L5-S1 are as a rule approached from the left side. Specialised selfretaining retractors as shown in the Figure 9 are a must for unperturbed exposure of the surgical field.

Preparation of the disc space and implant insertion: A complete discectomy that includes excision of the posterior annulus is followed by distraction of the disc space using a specially designed spreader. Optimum sizing of the implant is performed using trial implants, followed by implantation of the end-plate assembly. Care is taken to position the prosthesis in the midline in the coronal plane and posteriorly in the sagittal plane using fluoroscopy (Carm). Gradual distraction of the endplates to accommodate the polyethylene inlay is performed. Once the inlay gets snap-locked

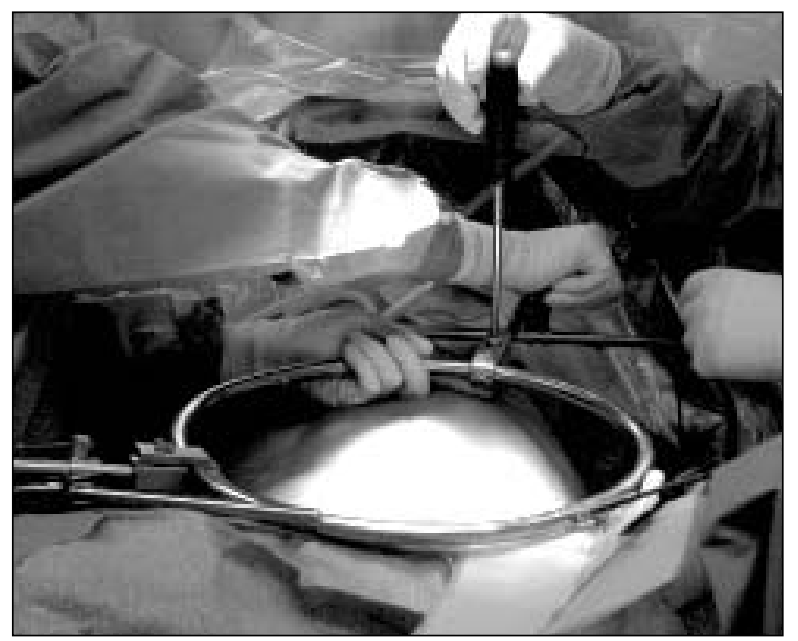

Figure 9: AO Synthes frame. An essential requirement for unperturbed view of the surgical field into the inferior endplate, the distractor is removed and the wound is closed in a routine manner.

Outcome studies: We have used Prodisc II since mid 2002. The outcome data has been collected prospectively. Thirty-three patients underwent single or multilevel implantation of Prodisc II prosthesis between 2002 and 2004. There were 17 males and 16 females with a mean age of 44 years (range, 29 to 65 years) at the time of surgery. Each patient had radiographic evidence of degenerative disc disease and severe back pain for a mean duration of 4.5 years (range, 0.5 to 24 years). A total of thirty seven discs were replaced; the replacements were performed at L5-S1 (17), L4-5 (16), L3-4 $4^{[3]}$ and L2-3 ${ }^{[1]}$ levels. The significant improvements in patient's symptoms are displayed in the Tables 1 and 2. We experienced complications in two cases. One patient developed a psoas hematoma that resolved with time while the other had a vertebral body fracture during implantation of the prosthesis. The fracture pattern was stable and no additional intervention was necessary.

\section{Complications}

The approach related complications essentially include potential injury to the major vascular and visceral structures. Access to anterior lumbar spine by a general/vascular surgeon may help in

Table 1: Demonstrating the gradual decrease in the frequency of back pain and improvement in the quality of life after total disc replacement

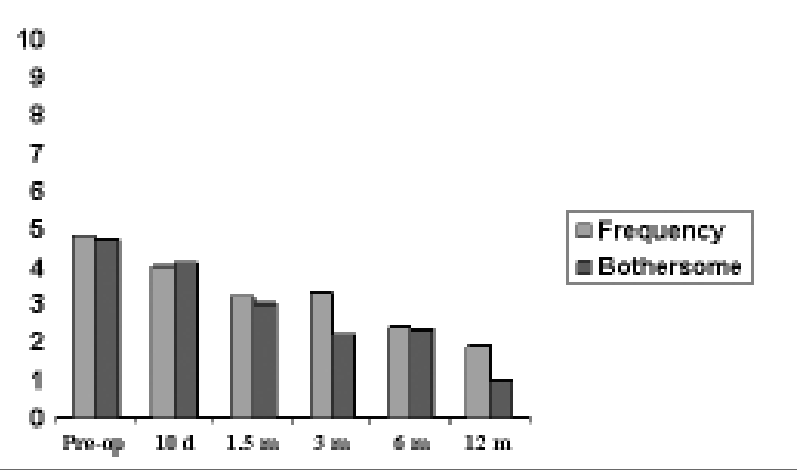

Table 2: Displays the decrease in pain intensity post-total disc replacement

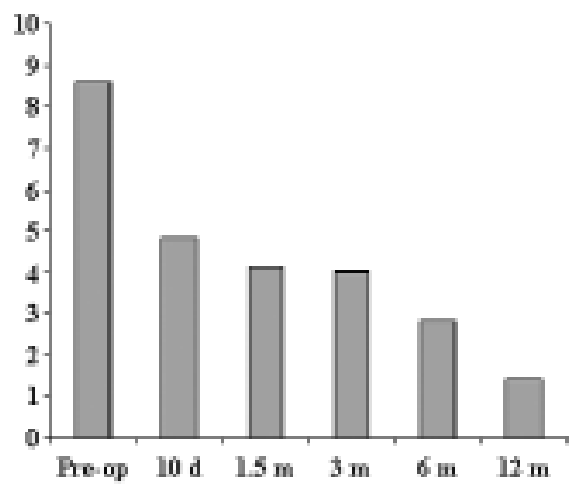


minimizing the incidence. The exposure to L5-S1 disc is relatively simple and can be approached by creating space at the division of aorta and inferior vena cava into common iliac vessels and ligating the middle sacral vessels. The approach to L4-5 disc needs extensive mobilisation of the aorta and inferior vena cava to the right side after ligation of the segmental vessels at L4 and iliolumbar vein at L5. The iliolumbar vein drains into the left common iliac vein and has a very variable course. Its course has to be traced carefully and the vein needs ligation to avoid any traction related injury. Regular pre-operative vascular studies such as Computer Tomography - angiography to better understand the local vascular anatomy have been suggested, but we do not think them to be necessary. Other approach related complications include abdominal wall and retroperitoneal hematomas deep vein thrombosis, retrograde ejaculation (inadvertent injury to superior hypogastric plexus) and distal embolisation by atheromatous plaques. ${ }^{[17-19]}$

Initial implant-related complications were a result of faulty $\operatorname{design}^{[20]}$ and involved subsidence and breakage of the prosthesis. With the present designs, isolated incidents of anterior prosthetic migration and dissociation of the SB Charite as well as Prodisc II polyethylene core has been noted. ${ }^{[17,19,21]}$ Revision surgery in the form of removal of prosthesis and spinal fusion as well as repositioning of the core has been performed to rescue the situation. Vertebral body fracture has been noted during insertion of prosthesis or in the postoperative period. ${ }^{[22,23]}$ Prosthesis malposition in the medio-lateral plane can be unforgiving and lead to lateral subsidence and eccentric facet loading. ${ }^{[19]}$ Anterior malpositioning is detrimental as it can reduce the prosthetic range of motion apart from increasing the loading on the facet joints. ${ }^{[24]}$ Implant subsidence can affect outcomes in several ways and is related to the size of the prosthesis in proportion to that of the endplate as well as bone mineral density. Residual back and leg pain have been reported and could be a result of inappropriate patient selection or surgeon related factors. ${ }^{[11,15,22,23,25]}$ These patients variably had pre-existent disc degeneration at other levels, facet arthrosis at the same level pre and post surgery, post-operative disc degeneration at adjacent levels, previous back surgeries in the form of nucleotomies, laminectomies etc. Surgeon related factors include asymmetrical insertion of prosthesis, wrong patient selection and extension of indications. Polyethylene wear debris, a major concern that is linked to osteolysis and implant-loosening in hip and knee replacements has neither been an issue in total disc replacement at short-term nor has been documented in animal studies and from human explants. ${ }^{[26]}$ Adjacent segment degeneration following total disc replacement at short-term interval (2 years) has ranged from $0 \%$ to $5 \%$ and a single medium term (9-years) follow-up study has reported $24 \%$ incidence on plain radiographs. ${ }^{[14,27]}$ The issue of adjacent level degeneration assumes importance as the implanted disc is expected to share some part of load-bearing by replicating the 'shock-absorber' function of the intervertebral disc, apart from allowing mobility. However, the present generation prostheses do not permit axial compression at the implanted level ${ }^{[28]}$ and it is probable that the load bearing task (shock-absorption capacity) of the implanted level may be transferred on to the adjacent segments. Heterotopic ossification which might paradoxically fuse the segment, has been documented in a few studies and strategies need to be developed to address the same. ${ }^{[19,29]}$

Epilogue: The major musculoskeletal challenges of developed countries are degenerative disorders due to the aging population and increased longevity. The patients' expectations are not limited to symptomatic relief but better quality of life and return to recreational activities. Spinal fusion, although having stood the test of time has not probably fulfilled its role in the treatment of chronic back pain as a result of operation related complications, graft site morbidity and altered physiological loading at the adjacent levels. The long awaited pursuit to design and insert an artificial disc to overcome some of the issues related to spinal fusion has at last been accomplished. The short-term results of randomized controlled trial results are comparable to spinal fusion, the midterm results of a single case series have shown mixed outcome and the long-term outcome is awaited. The procedure is in its early years and future research will focus on better formulation of indications, refinement of procedures, understanding of failure mechanisms and development of rescue strategies, etc.

\section{References}

1. Adams MA, Hutton WC. The mechanical function of the lumbar apophyseal joints Spine 1983;8:327-30.

2. Chung SA, Khan SN, Diwan AD. The molecular basis of intervertebral disc degeneration. Orthop Clin North Am 2003;34:209-19.

3. Ory FG, Rahman FU, Katagade V, Shukla A, Burdorf A. Respiratory disorders, skin complaints and low-back trouble among tannery workers in Kanpur, India. Am Ind Hyg Assoc J 1997;58:740-6.

4. Malhotra S, Bhatia GS, Pandhi P. Patterns of use of unconventional therapies in the medical outpatient department of a tertiary care hospital in India. J Ethnopharmacol 2001;75:71-5.

5. Sharma SC, Singh R, Sharma AK, Mittal R. Incidence of low back pain in workage adults in rural North India. Indian J Med Sci 2003;57:145-7.

6. Deyo RA, Nachemson A, Mirza S. Spinal-fusion surgery: the case for restraint. N Engl J Med 2004;350:722-6.

7. Silber JS, Anderson DG, Daffner SD, Brislin BT, Leland JM, Hilibrand AS, et al. Donor site morbidity after anterior iliac crest bone harvest for single-level anterior cervical discectomy and fusion. Spine 2003;28:134-9.

8. Weinhoffer SL, Guyer RD, Herbert M, Griffith SL. Intradiscal pressure measurements above an instrumented fusion: a cadaveric study. Spine $1995 ; 20: 526-31$.

9. McAfee PC. The indications for lumbar and cervical disc replacement. Spine J $2004 ; 4: 177 \mathrm{~S}-81 \mathrm{~S}$

10. Zeegers WS, Bohen LM, Laaper M, Verhaegen MJ. Artificial disc replacement with modular type SB Charite III: 2 year results in 50 prospectively studied patients. Eur Spine J 1999;8:210-7.

11. Bertagnoli R, Kumar S. Indications for full prosthetic disc arthroplasty: A coorelation of clinical outcome against a variety of indications. Eur Spine $J$ 2002;11;131-6.

12. Lemaire JP, Skalli W, Lavaste F, Templier A, Mendes F, Diop A, et al. Intervertebral disc prosthesis: Results and prospects for the year 2000. Clin Orthop 1997;337:64-76.

13. Hedman TP, Kostuik JP, Fernie GR, Hellier WG. Design of an intervertebral dise prosthesis. Spine 1991;16:\$256-60.

14. Cinoti G, David T, Postacehini F. Results of disc prosthesis after a minimum followup period of 2 years. Spine 1996;21:995-1000.

15. Huang RC, Lim MR, Girardi FP, Cammisa FP. The prevalence of contraindications to total disc replacement in a cohort of lumbar surgical patients. Spine $2004 ; 29: 2538-41$.

16. Delamarter RB, Fribourg DM, Kanim LE, Bae H. ProDise artificial total lumbar disc replacement: Introduction and early results from the United States clinical trial. Spine 2003;28:S167-75.

17. Griffith SL, Shelokov AP, Buttner-Janz K, LeMaire.JP, Zeegers WS A multicenter retrospective study of the clinical results of LINK SB Charite intervertebral prosthesis. The initial European experience. Spine 1994;19:1842-9. 
18. Zeegers WS, Bohnen LM, Laaper M, Verhaegen MJ. Artificial dise replacement with the modular type SB Charite III: 2-years results in 50 prospectively studied patients. Eur Spine J 1999;8:210-7.

19. van Ooij A, Oner FC, Verbout A.J. Complications of artificial dise replacement: A report of 27 patients with SB Charite dise. J Spinal Disord Tech 2003;16:369-83

20. Guyer RD, McAfee PC, Hochschuler SH, Blumenthal SL, Fedder IL, Ohnmeiss DD, et al. Prospective randomized study of the Charite' artificial disc:data from two investigational centers. Spine .J 2004;4:252S-9S.

21. Zigler JE, Burd TA, Vialle EN, Sachs BL, Rashbaum RF, Ohnmeiss DD. Lumbar spine arthroplasty. Early results using Prodisc II: A prospective randomized trial of arthroplasty versus fusion. Spine 2003;28:352-61.

22. Lemaire JP, Skalli W, Lavaste F, Templier A, Mendes F, Diop A, et al. Intrevertebra disc prosthesis. Results and prospects for the year 2000. Clin Orthop 1997:337:64-76.

23. Tropiano P, Huang RC, Girardi FP, Marnay T. Lumbar disc replacement: preliminary results with Prodisc II after a minimum follow-up period of 1 year. J Spinal Disord
Tech 2003;16:362-8.

24. Dooris AP, Goel VK, Grosland NM, Gilbertson LG, Wilder DG. Load-sharing between anterior and posterior elements in a lumbar motion segment implanted with an artificial disc. Spine 2001;26:E122-9.

25. Tropiano P, Huang RC, Girardi FP, Camissa Jr FP, Marnay T. Lumbar total disc replacement. Seven to eleven-year follow-up. J Bone Joint Surg Am 2005;87:490-6.

26. Anderson PA, Rouleau JP. Intervertebral disc arthroplasty. Spine 2004;29:2779 86.

27. Huang RC, Sandhu HS. The current status of lumbar total disc replacement. Orthop Clin N Am 2004;35:33-42

28. LeHuec JC, Kiaer T, Friesem T, Mathews H, Liu M, Eisermann L. Shock absorption in lumbar dise prosthesis: A preliminary mechanical study. J Spinal Disord Tech. 2003;16:346-51.

29. McAfee PC, Cunningham BW, Devine JD, Williams E, Yu-Yahiro J. Classification of heterotopic ossification (HO) in artificial disk replacement. Paper presented at North American Spine Society annual meeting: Montreal, Canada; 2002. 